\title{
Die devitaliseringsdialektiek van die skool: enkele fundamentele probleme
}

\author{
J.H. de Villiers \& \\ J.L. van der Walt \\ Departement Fundamentele en Historiese Opvoedkunde \\ Potchefstroomse Universiteit vir $\mathrm{CHO}$ \\ POTCHEFSTROOM
}

\begin{abstract}
Historically the school has been subject to a de-/vitalizing power-play fulfilled through the manipulative power of holders of power under the primacy of a specific religious ground morif.

The result has been that the school is seemingly experiencing an identity crisis because of the incomplete definition of its lask of educative teaching, because man/power-holders have historically been wont to regard himself/themselves as the justified determiner of meaning of his/their structures.

Subsequently the school's foundational function, its destinational function and its sphere of competence have been defined by way of apostatic ground motifs and secular points of departure.

- Thus the school has been subjected to a never-ending self-denying bipolar play of power which can be self-undermining. While no power-play can be driven to its fullest consequences, 'school reforms' have been self-abortive in nature.

There is therefore the demand to provide the school with a stable value system which for the Christian is situated in the creation-fall-nedemption religious ground motif which places man in a radical Creator-creature relationship.
\end{abstract}

\section{INLEIDING}

Die skool, as onderwysgetipeerde samelewingsverband, is deur die loop van die eeue, vanuit 'n reformatories-opvoedkundige hoek bekyk, steeds die slagoffer van 'n devitaliserende ('dodende', leweloos-makende) konflik. Dit is 'n konflik tussen allerlei soorte teenstellende, botsende, bi-polêre, nie-skoolse kragte van apostatiese aard, 'n konflik wat telkens dreig om die skool sy lewenskrag as samelewingsverband te ontneem. Hierdie dialektiese spel verloop in elke geval onder leiding en binne die konteks van die een of ander apostatiese (afvallige) religieuse grondmotief. Die spel neem die vorm aan van 'n hegemonie-kontrahegemonie-stryd, dit wil sé dit bestaan uit die strewe van die een pool van ' $n$ betrokke religieuse grondmotief om die ander pool daarvan te oorheers (De Villiers, 1991:243). Hierdie proses gee telkens aanleiding tot siklusse van konflik-en-herstrukturering en van spanning-en-ontwikkeling. Die spel 
laat dit dikwels lyk of die skool 'n historiese identiteitskrisis beleef en nie in staat is om homself te bevry van die manipulering deur historiese maghebbers of om te ontkom aan die trefkrag van bepaalde historiese gebeure nie (De Villiers, 1991:249).

Die vraag ontstaan waarom die skool in gebreke skyn te bly om aan hierdie manipuleringsmag van historiese maghebbers en gebeure te ontsnap, en nie in staat skyn te wees om sy eie bevoegdheidsterrein af te pen en te verdedig nie.

Die antwoord op hierdie vraag kan gevind word in 'n ontleding van die aard en enkele aspekte van die de-/vitaliseringsdialektiek wat hom deurentyd in die skool afspeel. So 'n ontleding word vervolgens onderneem vanuit 'n spesifiek reformatories-opvoedkundige perspektief.

\section{DIE VRAAGSTUK VAN BETEKENISSTRUKTURE VIR EN IN DIE SKOOL}

Die mens se natuurlike geneigdheid tot selfgenoegsame selfwetlikheid ('outonomie') gee daartoe aanleiding dat hy telkens aan die werklikheid en sy eie bestaan probeer sin (betekenis) gee aan die hand van die een of ander Archimedespunt wat self in die geskapene gevestig is. Hy poog dus om die singewing te laat realiseer onder leiding van 'n apostatiese (afvallige) religieuse grondmotief, soos die drie dualistiese grondmotiewe wat Dooyeweerd (1960:35-36) onderskei (vorm-materie; natuur-genade; natuur-vryheid). Hierdie religieuse grondmotiewe gee aanleiding tot bi-polêre spanninge vanweë hulle inherente dualistiese aard (byvoorbeeld die spanning tussen tradisie en progressie in die tradisionele Griekse skole in die tyd van die Sofiste; De Villiers, 1991:97). Die grondmotiewe gee ook aanleiding tot oppervlakkige singewing betreffende norme, waardes en kennisinhoude, en tot die ontstaan van apostatiese teorieë en praktyke aangaande die skool. Die ontstaan van kosmologiese verabsoluteringe (soos die meeste -ismes) kan ook hieraan gewyt word (Dooyeweerd, 1953:175; 1960:36).

Die resultaat van sodanige vertrekpunt en perspektief is dat die sin van die geskapene telkens vervlak word tot die aanvaarding van oppervlakkige norme en waardes wat gevolglik ook telkens geherformuleer en aangepas moet word by die eise van die kontingente situasie (vgl. Schoeman, 1983:11,78). Deur gebrek aan ware insig en vanweë sy teruggryp na die verlede (repristinasie) was Plato (429-347 v.C.) byvoorbeeld nie in staat om te ontsnap aan devitaliserende (verlammende) invloede op sy onderwysmodel en -praktyk nie (Republic, 363, 461; Laws, 659a). Plato wou naamlik die sosio-politieke onrus van sy tyd via die skool, dog tegelyk uitsluitlik vanuit sy houding van repristinasie oplos. Die gevolg hiervan was oplaaiende ontevredenheid met die toenemende irrelevansie van die skool vir die eise van die tyd. 


\section{DIE DEVITALISERENDE UITWERKING VAN DIE ONTOEREIKENDE DEFINISIE VAN DIE TAAK VAN DIE SKOOL EN VAN DIE SIN VAN DIE GESKAPENE}

Menslike handelinge kan getipeer word deur die een of ander idee of opvatting wat sin of betekenis aan die mens se bestaan bied (Fowler, 1987:4). Omdat die mens, soos aangedui in die vorige afdeling, daartoe neig om homself te beskou as die sinbepaler van die strukture wat hy tot stand bring (soos die skool) bly hy vasgevang in sekulère (wêreldse) en apostatiese (afvallige) religieuse vertrekpunte en perspektiewe. Die mens is gevolglik nie van nature daartoe in staat om tot ware insig te kom in die sin van die strukture wat hy tot stand bring en die teorieë wat hy daaroor saamstel nie.

Die mens se oorgawe van homself aan die een of ander religieuse grondmotief impliseer die totale betrokkenheid van sy ganse persoonlikheid, in al sy fasette, by die ontplooiing van gebeure en by die perspektiewe wat spruit uit sodanige religieuse grondmotief. Sy dade, ervaringe, denke en dies meer staan dus altyd in 'n betreklike verhouding tot die sinfokus wat hy as toepaslik aanvaar, en wat - in die geval van sekulêr-humanistiese denke en strukture - sigself manifesteer in allerlei dualistiese denkraamwerke vol interne spanninge (Schoeman, 1983:11; Duvenage, 1983:58).

Op grond hiervan gebeur dit dan meermale dat die skool se aktiwiteitsterrein omskryf word in terme van sulke dualistiese denkraamwerke. Die betrokke denkraamwerk kom na vore in die norme en die waardes wat in die omliggende gemeenskap geld, en aan die hand waarvan die kind in die skool begelei word (De Villiers, 1991:67-72).

Hierdie grondslag is ook bepalend vir die wyse waarop die funderings- en bestemmingsfunksie van die skool gesien word. So, byvoorbeeld, benader Van der Walt, (1985:202) die skool se funderingsfunksie as Christen, in teenstelling met die benaderinge wat in die volgende afdeling kortliks beskryf word.

\section{DEVITALISERENDE (VERLAMMENDE) KRAGTE WERKSAAM IN BESKOUINGE OOR DIE BESTEMMINGSFUNKSIE VAN DIE SKOOL}

Die bestemmingsfunksie van 'n samelewingsverband soos die skool, is ' $n$ formulering van die sin of betekenis van die bestaan daarvan (Stone, 1981:27-33). Van der Walt (1985:262) is byvoorbeeld van mening dat die bestemmingsfunksie van die skool in sowel die analitiese as die etiese funksie van die werklikheid geleë is omdat die skool gerig is op die gee van opvoedende onderwys. Volgens hierdie benadering van die sin van die skool behoort die skool naas sy taak van onderrig (didaskein), ook die leerling as opvoedeling se ganse aktstruktuur, maar in sonderheid sy etiese funksie (in 
aansluiting by die opvoedingstaak van die ouerhuis waar die opvoeding van die kinders eties bestem of getipeer is), te ontsluit sodat die kind se Godbestemde menswees tot sy volle reg kan kom. Didaskein behels die ontsluiting van die logies-analitiese funksie van die leerling, maar dan op so 'n wyse dat die kind (onder meer) ook eties verantwoordelik kan optree.

Voorgaande is 'n voorbeeld van singewing aan die (taak/doel van die) skool onder leiding van 'n anastatiese (op God-gerigte) religieuse grondmotief. (Op die meriete van die poging kan nie in die huidige konteks ingegaan word nie, aangesien dit op die rand van die argumentasielyn lè.) Daar was egter, in teenstelling met hierdie poging. regdeur die eeue diverse apostatiese beskouinge oor die bestemmingsfunksie van die skool.

Verskeie voorbeelde van sodanige apostatiese beskouinge kan in die geskiedenis aangetoon word. Aangesien dit nie moontlik is om binne die bestek van hierdie artikel die spesifieke denkraamwerke breedvoerig te bespreek nie, word volstaan met verwysing na enkele denkrigtings of verteenwoordigers van strominge. Die literatuur waarna verwys word, behandel die betrokke denkraamwerke in meer besonderhede:

- Die Sofiste, wat wegheweeg het van die gedagte van opvoeding tot deug, en die skool se bestemmingsfunksie in utilisme en pragmatistiese kennistoepassings in die hier en nou gesoek het (Kapp et al., 1985:50).

- Sokrates, wat op sy beurt die wetenskapsideaal en sedelike intellektualisme stel as die bestemmingsfunksie van die skool (in Athene)(vgl. Plato se Apology, 366c).

- Plato, wat in sy Republic (370-375) en Laws (711e) die wetenskapsideaal in politieke terme formuleer, en die (Atheense) skool se bestemmingsfunksie sien as die behoud van die status quo.

- Clemens van Alexandrië (in sy Stromateis, 1, 4, 28.1; 1, 16, 80.1), wat die natuurgenade-grondmotief aan die orde stel, 'n dualisme wat uiteindelik uitloop op die oorbeklemtoning van die genadepool, ook in die onderwys (vgl. Dooyeweerd, 1953:182-183).

- Die Skolastiek, wat gedurende die Middeleeue (ca. 5de-13de eeu n.C.) verval in 'n verstarring van die wetenskapsideaal as bestemming van die skoolse onderwys (vgl. Clouse, 1988:287).

- Die Renaissance (ca. 14de - 15de eeu n.C.), wat die bestemming van die skool in die immanente vryheidsgedagte soek (Lister, 1981:13). Dit het egter met verloop 
van tyd duidelik geword dat menslike vryheid deur die natuur-gedetermineerdheid van die wetenskapsideaal ingeperk is, en dat natuur en vryheid hierdeur in 'n direkte antitese te staan gekom het.

- In die moderne tyd (vanaf die 16de eeu) staan die mens se religieuse verwildering, sy disoriëntering en sy preokkupasie met vryheidsmodelle op die voorgrond. Dit neem die vorm aan van' $n$ alternerende oorhand van natuur en dan weer vryheid, en dié toedrag van sake vind weerspieëling in die bestemmingsfunksie van die skool. Die mens en werklikheid word hierdeur verskeurde entiteite; veel meer nog: mens en werklikheid kom hierdeur in 'n dissonante spanningsverhouding teenoor mekaar te staan (vgl. De Villiers, 1991:65,243).

Uit hierdie bondige en onvolledige vergelyking van sieninge aangaande die bestemmingsfunksie van die skool is dit duidelik dat

* die siening van die bestemmingsfunksie bepaal word deur die betrokke religieuse grondmotief, en

* dat die siening aangaande die bestemmingsfunksie van die skool skeefgetrek word as dit deur ' $n$ afvallige religieuse grondmotief gedetermineer word. Sodanige skeeftrekkinge lei daartoe dat die skool in die uitvoering van sy taak verkreupel en gedevitaliseer word.

\section{ONTOEREIKENDE OMSKRYWING VAN DIE SKOOL EN VAN SY FUNK- SIES AS 'N DEVITALISERENDE INVLOED OP DIE SKOOL}

Uit die redenasie in die vorige afdeling is dit duidelik dat die skool in sekulêre kringe nie volledig of ewewigtig beskryf word nie en dat dit tot eensydighede, verwringinge en skeefgetrokkenhede lei in die siening van die skool, veral wat die bestemmingsfunksie of doel daarvan betref. Soos blyk uit die voorbeelde in die vorige afdeling, is die skool volgens sodanige sieninge steeds onderworpe aan 'n nimmereindigende dialektiese kragtespel en aan eindelose hersienings en hervormingsprosesse. Omdat die skool onderworpe geag word aan 'n stryd tussen onversoenbare pole is die hervormingsaktiwiteite meestal futiel en selfs self-abortief van aard. Slegs 'n Skrifgefundeerde religieuse grondmotief as dunamis (krag) van die skool kan hierdie skynbare onoplosbare antitese waarin die skool hom bevind, verdryf. (Aan hierdie vraagstuk word vollediger aandag in 7 gegee.)

In die hande van die vermelde denkers bevind die skool homself in 'n kragspel wat selfs uitkring na die vraagstukke van die skool se bevoegdheidsterrein en sy vervleg- 
tingstrukture (vgl. De Villiers, 1991:250-257). Hierdie onstabiliteit maak die skool voortdurend die prooi van historiese maghebbers se invloed en laat die skool neig tot verandering. In die hande van sekulêr-humanistiese historiese maghebbers is die veranderinge meermale revolusionêr van aard (vgl. voorbeelde in 4 en 6), en nie juis Skrifgefundeerd-hervormend of konstruktief nie. Sulke veranderinge wat in en aan die skool aangebring word, kan nooit deurdring tot die ewige en onveranderlike sin van die skool wat 'n uitdrukking en konkretisering van die vaste wil van God vir die skool is nie. Verder is verdiepte insig in die teoretiese en voor-teoretiese grondslae van die skool en van die denke oor die skool, byvoorbeeld oor sy fundering en bestemming, sy bevoegdheidsterrein, ook nie moontlik nie. Deur hierdie tekortkoming het die skool in sekulère kringe telkens die prooi geword van grensoorskrydings deur ander verbandstrukture. Die beginsels van sowel soewereiniteit as universaliteit in eie kring is deur hulle of misgekyk of oortree (De Villiers, 1991:258-261).

Omdat die skool in sekulêr-humanistiese kringe nie vanuit 'n vaste en juiste verwysingspunt gedefinieer is en word nie, word die skool telkens ook gedetermineer op grond van allerlei nie-skoolse belange. Voorbeelde hiervan vind'n mens by Plato wat die skool in politieke terme benader het (Plato, Republic, 431, 549), by diegene wat die skool deur die tegnologie of die wetenskap wil laat determineer (1llich, 1973:11; 1974:10-15; Adorno, 1973; Gamm, 1972 en vele ander maatskappy-kritici se reaksies hierop), by diegene wat godsdienstige oorwegings (byvoorbeeld die genadepool) die deurslag wil laat gee (soos Clemens van Alexandrië, Stromateis, 5.1, 7.4); trouens by alle kosmologiese verabsoluteringe. Hervorminge nie vanuit 'n juiste oorsig- en insigpunt onderneem nie is dus uiteraard beperk in omvang, skeefgetrokke en dus selfverydelend van aard (vgl. ook De Villiers, 1991:3,242; Metzner \& Sharp, 1973:256266; McGurk, 1986:19; Illich, 1973:2,9,15,18).

\section{ONTOEREIKENDE DEFINIēRING VAN DIE SKOOL LEI TOT SELF- VERYDELING}

Die skool word duidelik gedevitaliseer (verkreupel, gedood, verydel in sy taak) deurdat die vermelde nie-skoolse kragte op hom inwerk en omdat sekulêre, apostatiese denkers nie in staat is om die skool te definieer in ander terme as juis hierdie vreemde, eksterne, nie-skoolse, dualistiese kragte en invloed nie. Enkele sprekende voorbeelde hiervan uit die Ooste en die Weste is die volgende:

Die Sjinese filosoof Confucius (551-478 voor Christus) kon byvoorbeeld nie die twee nie-skoolse kragte van sy tyd, naamlik instandhoudingsdenke en entrepeneursdenke, in 'n simbiotiese eenheid saambind en versoen nie omdat hy die beginsel van historiese determinisme as uitgangspunt van sy denke oor die skool aanvaar het (Confucius, 
Analects 2, 1,9).

Pestalozzi (1746-1827) het in sy tyd weer moeite om die nie-skoolse kragte van menslike waardigheid te versoen en saam te bind met dié van sosiale determinisme (Pestalozzi, 1979:22,28; Kilpatrick, 1969:viii).

John Dewey (1859-1952) het op sy beurt raakgesien dat die "leisured and moneyed class" in die Amerikaanse samelewing verkreupelend op die skool inwerk: die oorweldigende aandrang op die verskansing van hierdie klas mense in die samelewing se belange het gelei tot nadruk op intellektuele kennisinhoud, boekgeleerdheid, skolastisisme - en dus 'n uitgediende en dodende skoolfilosofie (Dewey, 1915:231-232; 1967:729). Teenoor die beskerming van die belange van hierdie bevoorregte klas staan die belange van die werkersklaskind. Die skool behoort volgens Dewey ruimte te maak vir die belange van laasgenoemde klas in die veranderde sosio-ekonomiese opset van die VSA.

Dit is uit hierdie, en die ander voorbeelde wat reeds in vorige afdelings van hierdie artikel vermeld is (kyk 4), duidelik dat die skool in die hande van sekulêr-humanistiese denkers onmagtig gemaak is om die botsende eise van die betrokke tyd wat van buite die skool kom te akkommodeer en om sy taak as samelewingsverband na behore te verrig. Die verklaring hiervoor is dat die norme en waardes wat denkers vir die skool stel in die betrokke veranderlike en kontingente situasies self gefundeer is en daaruit gepositiveer is. Hierdie toedrag van sake maak van die skool dan 'n funksie van die strydende kragte en lei tot die verydeling van sy werklike taak (vgl. Dooyeweerd, 1953:16). Die skool kan sy taak nie waarlik sinvol verrig solank dit vanuit die een of ander immanente sinperspektief benader, verstaan en gedefinieer word nie.

\section{AFLEIDINGS EN GEVOLGTREKKINGS}

Uit die voorgaande kan die volgende afgelei word:

- Die rede vir die feitlik deurlopende verwringing van die skool se funderings-en bestemmingsfunksie in die apostatiese denke oor die skool is geleë in die feit dat die mens in die proses van kultuurskepping van nature telkens in die strik trap om verabsoluteerde immanente waardes soos vorm, materie, genade, vryheid te beskou as deurslaggewend vir sy siening van die skool en sy taak. (vgl. De Villiers, 1991:35-37; 67-70; Dekker, 1985:49).

* Die sekulêre denker/'skool-filosoof' is skynbaar voortdurend besig om die struk- 
ture wat hy bedink te definieer aan die hand van die een of ander alles-oorheersende beginsel (vgl. McGurk, 1986:17-18). Om hierdie rede is die skool, soos Illich (1974:45-46; 52-53) dit stel, 'n prehistoriese mastodon wat uit voeling skyn te wees met die volle spektrum van die eise wat aan hom gestel is en word. Illich (1973:55; 1974:2,9,54) verkwalik byvoorbeeld die skool vir die feit dat die ongeskoolde massas, deur middel van die skool en deur burokrate se beheer oor die skool en ander kennisinstrumente, onder die oorheersing van die tegnokrasie gestel is en word (vergelyk ook die Neo-Marxiste en maatskappykritici soos Hans Pestalozzi (1979) en vele ander) (Jay, 1981).

- Dit is ook duidelik dat die sekulêre skool ten opsigte van die sin van sy bestaan deurlopend in die branding van dialektiese spanninge staan, en gevolglik dikwels die slagoffer is en was van 'n eindelose, futiele en devitaliserende (dodende, verkreupelende) kragtespel.

- Hieruit volg dat die skool in sekulêr-humanistiese denke op onvolledige wyse gedefinieer word en dat die diverse 'hervorminge' van die skool nie geslaagd kan wees nie (De Villiers, 1991:257-262).

- 'n Mens kan ook tot die gevolgtrekking kom dat daar 'n behoefte bestaan om op so 'n wyse deur besinning oor die skool en sy taak aan die skool beslag te gee dat die skool as 'n lewenskragtige struktuur, sonder die gemelde belemmeringe, kan funksioneer. Die oplossing vir hierdie probleem van die skool lê moontlik in 'n ewewigtige teorie aangaande die wetsy van die skool wat saamhang met die subjeksy daarvan. Met hierdie teorie kan die stabiele, bewarende, perenniële aspekte van die skool (die wetsy) gekoppel word met die veranderlike, vernuwende, kontingente aspekte daarvan (die subjeksy), sonder om die een of ander aspek van die skool en sy taak te verabsoluteer (vgl. De Villiers, 1991:270-279). So 'n teorie het as grondslag en fondament ' $n$ stabiele norm- en waardesisteem wat op sy beurt gefundeer is in 'n Skrifmatige religieuse grondmotief en sinperspektief.

Op grond van hierdie vertrekpunte is dit duidelik dat verandering en vernuwing 'n toekomsgerigte sinperspektief moet hê: beweging en vitaliteit dui op 'n bestemming van alles in en by God. Verandering en vernuwing het egter ook 'n eietydse dwingendheid: dit moet die gebroke werklikheid in behandeling neem en probeer regstel. Daar bestaan dus vir die Skrifgefundeerde denker (in casu oor die skool) legitieme veranderlikes in die kontingente situasie (subjeksy), maar hulle word gesien in die raamwerk van die ewige onveranderlike aspekte (wetsy) van die werklikheid. Albei hierdie aspekte, subjeksy en wetsy van die werklikheid (in hierdie geval van die skool) wat uiteindelik 'n eenheid vorm, mekaar aanvul, mót geakkommodeer word in ' $n$ teorie oor die skool en sy taak. Hierdie eenheid moet 
nagestreef word indien 'n lewenskragtige organisme van die skool gemaak wil word; 'n organisasie wat steeds aan sy basiese struktuur (Goddelike bouplan) getrou kan bly maar tog doeltreffend kan aanpas by die eise van die betrokke tyd.

Die Skrifgefundeerde denker moet dus na 'n vaste sinpunt vir die skool soek, en dit vind hy in Christus wat die sin van alles in die skepping is (vgl. Joh. 1:1-14). Hierdie perspektief op die sin van die ganse werklikheid plaas die mens en al sy strukture (ook die skool) onder die eenduidige (nie-dualistiese) leiding van die religieuse grondmotief van skepping-sondeval-verlossing in Jesus Christus in gemeenskap met die Heilige Gees. Sodoende word die mens en sy strukture (in hierdie geval die skool) in 'n radikale en eenduidige verhouding met die Skepper van alle dinge (ook die skool) geplaas en in 'n eenheid in God saamgebind.

Langs genoemde weg word die devitaliserende dialektiek waaraan die skool in sekulêre kringe onderworpe is uit die weg geruim, kan die skool in die regte perspektief gesien word en kan hy sy taak uitvoer op 'n wyse wat in ooreenstemming is met sy Godgegewe struktuur.

\section{BIBLIOGRAFIE}

ADORNO, T. 1973. Negative Dialcktik. Frankfurt-am-Main : Suhrkamp.

CLEMENS ALEXANDRINUS, V. 1914. Oud-Christelijke Geschriften. Vlechtwerken I. (Stromateis.) In Nederlands vertaal deur H.U. Meyboom, red. Leiden : Sijthoff. 194p.

CLOUSE, R.G. 1988. Die bloeityd van die Westerlike kerk (In Dowley, T., red. Die geskiedenis van die Christendom. Vertaal deur Ludwig Visser. Kaapslad : Struik. p. 252-299.)

CONFUCIUS. 1895. The Confucion Analects: A Translation with Annolations and an Introduction by W. Jennings. London : Routledge. (Sir John Lubbock's Hundred Books, 93.) 224p.

DEKKER, E.l. 1985. Antropologiese voorveronderstellings, opvoeding, onderwys en opvoedkunde. (In Van der Wall, J.L., Dekker, E.I. \& Van der Walt, I.D. Die opvoedingsgebeure: 'n Skrifmatige perspektief. Potchefstroom : PU vir CHO. Recks F. Instituut vir Reformatoriese studies. F.3 Versamelwerke nr. 18. p. 92-197.)

DE VILliERS, J.H. 1991. Die de-/vitaliseringsdialcktick van die skool. Potchefstroom. (Proefskrif (Ph.D.)-PU vir CHO.) 315p.

DEWEY, J. 1915. The Child and the Curriculum. Contributions to Education. Number V. Chicago : The University of Chicago Press. 39p.

DEWEY, J. 1967. The School and Socicty. London : The University of Chicago Press. 159p.

DOOYEWEERD, H. 1953. A New Critique of Theoretical Thought, vol. 1. Philadelphia : Presbyterian and Reformed Publishing Co. 566p.

DOOYEWEERD, H. 1960. In the Twilight of Western Thought. Philadelphia : Presbyterian and Reformed Publishing Co. 195p.

DUVenaGe, B. 1983. Roeping en wetcnskap. Potchefstroom : Bentoti. 268p.

FOWLER, S. 1987. Christian Education Distinctives. Potchefstroom : PU for CHE. (Wetenskaplike bydracs of the PU for CHE. Series F : Institute for Reformational Studies. F2 Brochures. Number 39.) 216p.

GAMM, HJ. 1972. Das Elend der Spätburgerlichen Pädagogik. München : List. 
ILLICH, I. 1973. Energicverbruik en maatschappelijke tegenstellingen. Baarn : Het Wereldvenster. 80p. ILLICH, I. 1974. Deschooling Society. London : Calder \& Boyard. 116p.

JAY, M. 1981. Dialektische Phantasie. Frankfurt-am-Main : Fischer.

KAPP, P.H., MOLL, J.C., SCHOLTZ, P.L., DE JONGH, P.S. \& GRUNDLINGH, L.W.F. 1985 Geskiedenis yan die Westerse beskawing. Deel I. Pretoria : HAUM. 434p.

KILPATRICK, W.H. 1969. Introduction. (In Pestalozzi, H. Aphorisms. New York: Greenwood Press. p. i-xii.)

LISTER, I. 1981. Deschooling Revisited. (In After Deschooling What? With an Introduction by lan Lister. London: Writers and Readers Publishing Co-Operative. p. 4-30.)

McGURK, NJ. 1986. Education and the Open Society. Educational Joumal, 96(2) : 16-20, September.

METZNER, S. \& SHARP, V.F. 1973. Education in China and the Death of Creativity. Phi Delto Kappan, 54(5):265-266, December.

PESTALOZZI, H.A. 1979. Nach uns die Zukunft. München: Kösel.

PLATO. 1952. Plato IX. Laws. In two volumes, vol, 1 and 2. With an English translation by R.G. Bury. London : Heineman. 501p.

PLATO. 1953. Apology. (In Plato I. With an English translation by H.N. Fowler. Euthyphro, Apology, Crito, Phacdo, Phaedrus. London : Heineman. p. 61-145.)

PLATO, 1985. The Republic. Vertaal deur dr. A.D. Lindsay. London : Dent. 325p

SCHOEMAN, P.G. 1983. Wysgerige pedagogick. Pretoria : Sacum. 309p

STONE, H.J.S. 1981. Die aard en struktuur van die skool. Potchefstroom : PU vir CHO. (Educantulus 1. 'n Reeks monografieë oor opvoedkunde onder redaksie van prof. H.J.S. Stone.) 33p.

VAN DER WALT, I.D. 1985. Samelewingsteoretiese grondslae van die opvocdkunde. (In Van der Walt, J.L., Dekker, E.I. \& Van der Walt, I.D. Die opvoedingsgebcure: 'n Skrifmatige perspektief. Potchefstroom : Reeks F: Instituut vir Reformatoriese Studies. F3 Versamelwerk nr. 18. p. 238 272.) 